\title{
Advances in the Pharmacologic Management of Atrial Fibrillation
}

\author{
Alexander Burashnikov, PhD, FHRS and Charles Antzelevitch, PhD, FHRS * \\ Masonic Medical Research Laboratory, 2150 Bleecker Street, Utica, NY 13501, USA
}

\section{Keywords}

Atrial fibrillation; Antiarrhythmic drugs; Cardiac arrhythmia; Electrophysiology; Pharmacology

\begin{abstract}
Atrial fibrillation (AF) is a growing clinical problem associated with increased morbidity and mortality. The rising prevalence of AF is largely due to the increase in the aging sector of the population. $\mathrm{AF}$ is expected to reach epidemic proportions, increasing from about 2.66 million to 15 million affected people by 2050 in the United States alone. ${ }^{1}$ Currently available tools for the treatment of patients with AF remain far from ideal. The development of safe and effective treatments for AF is one of the greatest unmet medical needs. There is an emerging paradigm shift in the management of patients with $\mathrm{AF}$ from electric end points (rate and rhythm control) to more general end points (such as mortality and morbidity). ${ }^{2}$ This review describes current strategies and novel developments in the pharmacologic management of AF (Fig. 1).
\end{abstract}

\section{RHYTHM CONTROL}

Rhythm control strategies are focused on the maintenance of sinus rhythm, with its restoration when required. Rhythm control can be achieved with antiarrhythmic agents (AADs), catheter ablation, electric cardioversion, or, rarely, by using surgical techniques. AADs are also used to maintain sinus rhythm after catheter ablation or cardioversion. Although the use and efficacy of catheter ablation-based approaches in AF rhythm control treatment have increased significantly over the past decade, AADs remain the first line therapy for rhythm management of most patients with AF. 3,4 The recent European Society of Cardiology (ESC) guidelines indicate that left atrial ablation may be considered as the frontline therapy in select patients with paroxysmal symptomatic AF (ie, relatively young individuals with minimal to no heart disease). ${ }^{4}$

\section{Modulation of Ion Channel Activity}

Most AADs in current clinical use, and those under development, exert their anti-AF actions exclusively or primarily via modulation of cardiac ion channel activity. Agents that inhibit the early sodium channel current $\left(\mathrm{I}_{\mathrm{Na}}\right)$, such as flecainide and propafenone, have proven to be effective in terminating paroxysmal episodes of AF but far less effective in dealing with persistent AF. Because of a proclivity for arrhythmogenesis, these agents are contraindicated in patients with acute coronary syndrome and structural heart disease, which account for more than $70 \%$ of patients with AF. ${ }^{3}$ Agents that as a primary action inhibit the rapidly

() 2011 Elsevier Inc. All rights reserved.

*Corresponding author. ca@mmrl.edu.

Conflict of interest statement: Dr Antzelevitch is a consultant to Gilead Sciences and AstraZeneca and received grant support from Gilead Sciences, AstraZeneca, and Merck and Cardiome. 
activating delayed rectified potassium current $\left(\mathrm{I}_{\mathrm{Kr}}\right)$, such as dofetilide, also effectively terminate paroxysmal AF and less effectively persistent AF but these drugs also cause acquired long QT syndrome and may be associated with the development of torsades de pointes arrhythmias. The success rate for terminating persistent $\mathrm{AF}$ is greater for $\mathrm{I}_{\mathrm{Kr}}$ blockers than for $\mathrm{I}_{\mathrm{Na}}$ blockers. ${ }^{3}$ The efficacy of long-term maintenance of sinus rhythm with $\mathrm{I}_{\mathrm{Na}}$ and $\mathrm{I}_{\mathrm{Kr}}$ blockers (at 1 year) does not exceed 50\%. ${ }^{5}$ Amiodarone, a mixed ion channel blocker, is widely used for the long-term maintenance of sinus rhythm and is effective in $65 \%$ of cases at 1 year. $^{6}$ Advantages of amiodarone are that it can be safely used in most patients with structural heart disease and its application is rarely associated with ventricular proarrhythmia. A major disadvantage of the long-term use of amiodarone is the relatively high rate of multiorgan toxicity. Dronedarone, a derivative of amiodarone, was approved by the Food and Drug Administration (FDA) in 2009 for the treatment of patients with AF, with the indication that it reduces cardiovascular hospitalization. Anti-AF efficacy of dronedarone is superior to placebo but significantly inferior to that of amiodarone. ${ }^{7-9}$ Although dronedarone is generally safer than amiodarone, its major drawback is its apparent action to aggravate congestive heart failure (CHF) in patients with preexisting severe CHF (New York Heart Association [NYHA] class IV). ${ }^{10}$ Amiodarone has also been reported to increase mortality in NYHA class IV patients. ${ }^{11}$

It is speculated that rhythm control with AADs would be preferable for most patients with $\mathrm{AF}$ if safer and more effective anti-AF drugs were available. ${ }^{12,13}$ Thus, development of safe and effective AADs for rhythm control management of AF is highly desirable. The search for new anti-AF AADs focuses largely on the delineation of atria-specific or atria-selective targets/agents, as well as on "an improvement of existing AADs" (see Fig. 1). Atriaselective strategies ${ }^{14}$ are designed to avoid or reduce the risk of induction of ventricular proarrhythmia. Atria-specific targets for AF treatment are those that are present exclusively or almost exclusively in the atria and include the ultrarapid delayed rectified potassium current $\left(\mathrm{I}_{\mathrm{Kur}}\right)$, the acetylcholine-activated inward rectifying potassium current $\left(\mathrm{I}_{\mathrm{K}-\mathrm{ACh}}\right)$, and the constitutively active (CA) $\mathrm{I}_{\mathrm{K}-\mathrm{ACh}}$, which does not require acetyl-choline or muscarinic receptors for activation. ${ }^{15}$

$\mathrm{I}_{\mathrm{Kur}}$ is among the most investigated ion current and until recently, it was widely considered to be the most promising target for the treatment of AF. ${ }^{15}$ However, it is becoming increasingly evident that $\mathrm{I}_{\mathrm{Kur}}$ block alone is unlikely to be sufficient to effectively suppress AF. ${ }^{16,17}$ In fact, inhibition of $\mathrm{I}_{\mathrm{Kur}}$ may promote AF in nonremodeled atria. ${ }^{18}$ The contribution of $\mathrm{I}_{\mathrm{Kur}}$ in AF may be relatively small because $\mathrm{I}_{\mathrm{Kur}}$ density is reduced with the acceleration of activation rate. ${ }^{19} \mathrm{I}_{\mathrm{Kur}}$ density is also reduced in cells isolated from atria of patients with chronic $\mathrm{AF} .{ }^{20}$ Although block of $\mathrm{I}_{\mathrm{Kur}}$ alone may not be effective, when combined with $\mathrm{I}_{\mathrm{Kr}}$ and/or $\mathrm{I}_{\mathrm{Na}}$ inhibition, the role of $\mathrm{I}_{\mathrm{Kur}}$ in anti-AF actions may be substantial. ${ }^{16,21}$

Block of $\mathrm{I}_{\mathrm{K}-\mathrm{ACh}}$ may be a useful target in clinical cases of vagally mediated AF. CA $\mathrm{I}_{\mathrm{K}-\mathrm{ACh}}$ can be an atria-specific and pathology-specific target for $\mathrm{AF}$ treatment. Indeed, $\mathrm{CA} \mathrm{I}_{\mathrm{K}-\mathrm{ACh}}$ is only marginally present in healthy nonfibrillating atria and is significantly increased in persistent or chronically fibrillating atria. ${ }^{15,22} \mathrm{CA} \mathrm{I}_{\mathrm{K}-\mathrm{ACh}}$ could be a valuable target for safe $\mathrm{AF}$ treatment, provided it can be inhibited independent of the conventional $\mathrm{I}_{\mathrm{K}-\mathrm{ACh}}$ channels present in many organs other than the heart (eg, in the central nervous system). However, no selective $\mathrm{CA}_{\mathrm{K}-\mathrm{ACh}}$ blocker is available now.

Recent studies have focused on the small conductance calcium-activated potassium channels (SK channels) present in the hearts of mice, rats, rabbits, and humans. ${ }^{23,24}$ There are 3 SK channel isoforms in the heart (ie, SK1, SK2, and SK3); SK1 and SK2 are selectively expressed in atria versus ventricles. Inhibition of the SK channels or genetic 
ablation of SK2 causes electrophysiological changes selectively in atria. ${ }^{24,25}$ Block of SK channels can effectively terminate AF and prevent the recurrence of arrhythmia in experimental rat, guinea pig, and rabbit models of $\mathrm{AF}^{24}$ Thus, pilot experimental data suggest that SK channels could be an atria-selective pharmacologic target for AF suppression. However, the role of SK channels in large animals and humans remains poorly defined, as are the functional consequences of modulation of SK channels, including the proarrhythmic potential. For instance, it has been reported that genetic ablation of SK2 channels is associated with the induction of AF in mice. ${ }^{25}$

Atria-selective ionic channel targets are those that are present in both the chambers of the heart but their inhibition produces greater effects in atria than ventricles. These targets include $\mathrm{I}_{\mathrm{Na}}$ and $\mathrm{I}_{\mathrm{Kr}}$ channels (see Fig. 1). $\mathrm{I}_{\mathrm{Na}}$ blockers (such as ranolazine, AZD7009, AZD1305, and long-term amiodarone) produce atria-selective depression of $\mathrm{I}_{\mathrm{Na}}$ and $\mathrm{I}_{\mathrm{Na}^{-}}$ dependent parameters and effectively suppress AF in the canine heart at concentrations causing little to no electrophysiological changes in the ventricles. ${ }^{16,17,26-28}$ A selective $\mathrm{I}_{\mathrm{Kr}}$ block produces a greater prolongation of action potential duration (APD) and effective refractory period in atria versus ventricles at normal activation rates. ${ }^{16,27,29}$ All atriaselective identified $\mathrm{I}_{\mathrm{Na}}$ blockers also inhibit $\mathrm{I}_{\mathrm{Kr}}$ and preferentially prolong APD in atria. APD prolongation in atria has been shown to potentiate the development of use-dependent block of $\mathrm{I}_{\mathrm{Na}}$ (Fig. 2). ${ }^{16,26,27}$ Atria-selective $\mathrm{I}_{\mathrm{Na}}$ blockers, including ranolazine, amiodarone, AZD7009, and AZD1305, effectively suppress AF in the clinic. ${ }^{30-33}$

With the exception of $\mathrm{I}_{\mathrm{Kr}}$ blockers, such as dofetilide, currently available drugs showing anti-AF efficacy (such as amiodarone, dronedarone, flecainide, propafenone, vernakalant, quinidine) as well as promising investigational AADs (such as ranolazine) inhibit multiple ion channels. Among these multiple ion channel blockers, those that inhibit $\mathrm{I}_{\mathrm{Na}}$ and exhibit rapid dissociation kinetics (such as amiodarone, dronedarone, vernakalant, and ranolazine) rarely, if ever, produce ventricular proarrhythmia. In contrast, AADs (eg, propafenone and flecainide) that inhibit $\mathrm{I}_{\mathrm{Na}}$ and exhibit slow dissociation kinetics are capable of inducing ventricular proarrhythmia and are contraindicated in structurally compromised hearts as well as in acute coronary syndrome. Another important side effect of AF therapy with slowly dissociating $\mathrm{I}_{\mathrm{Na}}$ blockers is an induction of atrial flutter with 1:1 conduction to the ventricles. Of note, rapidly dissociating $\mathrm{I}_{\mathrm{Na}}$ blockers tend to be atrial selective, whereas slowly dissociating blockers are not. ${ }^{16}$ Vernakalant recently received FDA approval for its intravenous administration for acute cardioversion of paroxysmal AF and rapid termination of postoperative $A F .{ }^{34,35}$

Recent experimental studies conducted in canine atrial and ventricular preparations demonstrate that the combinations of long-term amiodarone and short-term ranolazine as well as short-term dronedarone and ranolazine (at a relatively low ranolazine concentration; $5 \mu \mathrm{M})$ cause a potent synergistic atria-selective depression of sodium channel-mediated parameters (Fig. 3). ${ }^{36,37}$ These combinations were shown to effectively suppress and prevent the induction of AF, while exerting little to no electrophysiological influence in the ventricles. ${ }^{36,37}$ The combination of dronedarone and ranolazine is likely to be associated with little to no adverse effects or organ toxicity because each has a safe clinical record. ${ }^{38,39}$ Available data indicate that dronedarone alone is not an atria-selective agent. $37,40,41$

The long-term adverse effects of AADs, both arrhythmic and nonarrhythmic, remain difficult to predict. ${ }^{10,42}$ Clinical experience indicates that an optimal long-term risk-benefit ratio is best achieved with multiple ion channel blockers, which inhibit $\mathrm{I}_{\mathrm{Na}}$ with rapid dissociation kinetics, as well as late $\mathrm{I}_{\mathrm{Na}}$ and $\mathrm{I}_{\mathrm{Kr}} \cdot{ }^{16,17}$ 


\section{Upstream Therapy}

AF is commonly associated with both electric and structural atrial abnormalities as well as with a number of other conditions such as oxidation injury, inflammation, stretch, ischemia. Many of these AF-associated abnormalities are caused by intracardiac and extracardiac diseases, including heart failure, hypertension, coronary artery diseases, myocardial infarction. Oxidative stress may induce inflammation, and both of these factors may promote atrial structural remodeling (ie, interstitial fibrosis, fibroblast proliferation, accumulation of collagen, dilatation, hypertrophy). Atrial structural remodeling can be principally involved in the development and maintenance of $\mathrm{AF}$ and may play a greater role in AF maintenance than electric atrial abnormalities. ${ }^{43}$ Amelioration of diseases and/or conditions/factors promoting atrial structural remodeling (such as hypertension, heart failure, infarction, oxidative stress, inflammation, stretch) may reduce AF occurrence. A relatively novel investigational approach for $\mathrm{AF}$ rhythm control management is upstream therapy, which targets structural remodeling in the atria, factors/diseases that promote such remodeling, or both. ${ }^{44}$

The precise contribution of structural remodeling, inflammation, oxidative injury, ischemia, and stretch (and numerous mediating factors/signaling pathways) in the development of AF remains poorly understood and is likely to vary significantly among different $\mathrm{AF}$ pathologies. ${ }^{45}$ Experimental and clinical evidence indicate that angiotensin-converting enzyme inhibitors, angiotensin receptor blockers, statins, aldosterone antagonists, and $\omega-3$ polyunsaturated fatty acids may or may not be beneficial in the management of AF. ${ }^{44,46,47}$ The anti-AF mechanisms of these interventions are not well established and are presumed to be largely because of their antihypertensive, antiinflammatory, and antioxidative stress actions, reducing structural remodeling.

Several factors have been identified to mediate the generation of atrial fibrosis/ inflammation/oxidative stress, including angiotensin II, angiotensin II receptors, transforming growth factor $\beta 1$, mitogen-activated protein kinase, platelet-derived growth factor, peroxisome proliferator-activated receptor $\lambda$, Janus kinase, Rac1, NADPH oxidase, signal transducers and activators of transcription, and calcineurin. ${ }^{45,48}$ The precise causeeffect relationship of the changes observed in all these factors/cascades with AF is difficult to establish, so some of these changes could be the consequences of AF. Most of the current clinical data on upstream AF therapy are derived from observational studies that were not sufficiently powered, and hence, practical clinical applicability of the upstream therapies remains to be determined. ${ }^{46,47}$

\section{Other Preclinical Rate Control Strategies}

Several investigational approaches for the pharmacologic treatment of AF have some supporting experimental evidence but remain far from clinical testing (such as modulation of gap junctions or intracellular calcium activity). ${ }^{17}$ It is well recognized that conduction disturbances may have a pivotal role in the generation of AF. Gap junctions, composed of proteins called connexins, are complexes that connect myocardial cells through lowresistance pathways and affect the propagation of excitation in the myocardium. Improving gap junction conductance using the gap junction modulator rotigaptide suppresses AF in a canine chronic mitral regurgitation $\mathrm{AF}$ model ${ }^{49}$ and canine acute ischemia AF model. ${ }^{50}$ Rotigaptide, however, did not affect $\mathrm{AF}$ development in $\mathrm{AF}$ models associated with heart failure or atrial tachypacing. ${ }^{49,50}$ An apparent limitation of gap junction therapy for the treatment of $\mathrm{AF}$ is that atrial conduction slowing in most patients with $\mathrm{AF}$ occurs largely due to structural remodeling. As a result, the practical applicability of gap junction therapy is likely to be limited only to selective AF cases in which an alteration in gap junction function is a principal cause of AF. 
A growing body of evidence suggests that abnormal intracellular calcium homeostasis, observed in experimental and clinical AF studies, plays a role in the generation of AF and that normalization of sarcoplasmic reticulum (SR) calcium release may be a potential therapeutic approach. ${ }^{51-54}$ An increase in spontaneous SR calcium release as well as a significant SR calcium leak have been observed in atrial myocytes isolated from humans and dogs with AF by tachypacing-induced atrial remodeling. ${ }^{52,53}$ Although the pharmacologic modulation of these arrhythmogenic mechanisms might be of benefit, the challenge is to regulate SR calcium release and intracellular calcium loading without compromising myocardial contractility.

\section{RATE CONTROL}

Rate control strategy is focused on preventing the detrimental effects of rapid atrial activation on the ventricles via the reduction of ventricular rate, without specific efforts to terminate AF or maintain sinus rhythm. Major harmful consequences of sustained nontreated AF on ventricles are the development of cardiomyopathy and heart failure. Rate control is most often achieved with the use of pharmacologic agents such as $\beta$-blockers, calcium channel blockers, and digoxin. These drugs reduce the excitability of the atrioventricular node, decreasing the number of activations conducted to the ventricles from the fibrillating atria.

It is commonly believed that normality (ie, sinus rhythm) is better than abnormality (ie, AF and related rate control). Indeed, patients with $\mathrm{AF}$ who are maintained in sinus rhythm (with or without AADs) have a better survival rate and quality of life than those in whom AF persists, ${ }^{55-57}$ although this is not always the case. ${ }^{58}$ Currently available AADs do not reliably maintain sinus rhythm over the long term without the substantial risk of adverse effects in many patients with AF. Results from a number of multicenter, randomized, and prospective clinical trials suggest that rhythm control strategies with currently available AADs are not superior to rate control in terms of morbidity and mortality. ${ }^{59-62}$ It likely that the adverse effects of using available AADs for rhythm control, secondary to extracardiac toxicity and ventricular proarrhythmia, balances or exceeds the benefit derived from a limited capability of these AADs to maintain sinus rhythm. Due to the limitations and shortcomings of the AAD-based rhythm control strategy, significant numbers of patients with $\mathrm{AF}$, who are commonly relatively old and asymptomatic, benefit more from a rate control than a rhythm control strategy. Individuals with permanent AF may have no therapeutic choice but rate control. Rate control may have some important advantages over AAD-based rhythm control, such as a reduced rate of hospitalization and elimination of the need for repeated cardiovesion. $.59,60$

Current ACC and AHA guidelines for the management of patients with AF suggest that ventricular rate in the rate control approach should be less than 80 beats per minute at rest. ${ }^{3}$ This recommendation is largely based on the assumption that in patients with AF, (1) the closer the ventricular rate is to the normal sinus rate, the lower the probability of developing AF-induced complications and (2) the benefit from strict rate control is greater than the entailed risk of the adverse effects. Recent data from a large randomized clinical trial the rate control efficacy in permanent atrial fibrillation: a comparison between lenient versus strict rate control II (RACE-II) suggest that strict rate control is not superior to lenient rate control (ie, ventricular resting rate in patients with permanent $\mathrm{AF} \leq 80$ and 110 beats per minute, respectively) for preventing cardiovascular morbidity and mortality. ${ }^{63}$ Previous retrospective analysis of the Atrial Fibrillation Follow-up Investigation of Rhythm Management (AFFIRM) trial also did not find differences in morbidity and mortality or quality of life in strict versus mild rate controls. ${ }^{64}$ Considering the results of RACE-II, as well as the practical convenience and advantages of lenient versus strict rate controls (easier 
to achieve with fewer outpatient visits), the new ESC guidelines suggest that lenient rate control may be preferable in select patients with permanent $\mathrm{AF}^{4}$

Aspirin, a less effective but safer agent than warfarin, is often prescribed to low-risk patients with $\mathrm{AF}$ (risk of stroke $\leq 2 \%$ per year) ${ }^{65}$ Rate and rhythm control with AADs are not mutually exclusive, that is, many AADs used for rhythm control (such as amiodarone, dronedarone, sotalol) possess rate control abilities as well, which may contribute to their total therapeutic positive actions.

\section{ANTICOAGULATION}

Stroke is a major detrimental consequence of AF. The incidence of stroke is increased 5-fold in patients with $\mathrm{AF}$ compared with those without AF. ${ }^{66}$ Most patients with AF, regardless of the choice of rhythm or rate control strategies, require anticoagulation therapy to reduce the risk of stroke. The decision is commonly made with the aid of the CHADS2 score that counts the following risk factors: CHF, hypertension, age greater than 75 years, diabetes mellitus (each scored as 1), and prior stroke or transient ischemic attack (each scored as 2). Patients with AF with a score of 2 or more are considered to have a high risk for stroke (>4\% annually). The most commonly used anticoagulants include vitamin K antagonists; among them, warfarin is most widely prescribed for patients at intermediate to high risk for stroke. ${ }^{67}$ Aspirin, a less effective but safer agent than warfarin, is often prescribed to lowrisk patients with $\mathrm{AF}$ (risk of stroke $=2 \%$ per year) ${ }^{65}$ Antiplatelet agents are also anticoagulants. Randomized clinical trials have consistently shown that in high-risk AF patients, warfarin therapy results in reduction of about $65 \%$ in the incidence of stroke whereas antiplatelet agents (clopidogrel and aspirin) reduce it by approximately $20 \% .{ }^{68}$

A major complication of anticoagulant therapy is bleeding, and so before the initiation of antithrombotic therapy, a risk-benefit ratio needs to be evaluated. The risk of bleeding is increased with age and diabetes. ${ }^{65,68}$

Warfarin, despite its limitations, remains the best available anticoagulant for high-risk patients with AF. ${ }^{67}$ Several novel anticoagulants (such as dabigatran, rivaroxaban, edoxaban, apixaban) are currently in their late stages of clinical development for providing an alternative to warfarin, which is capable of providing safe and effective anticoagulation. Notably, in the Randomized Evaluation of Long-Term Anticoagulation (RE-LY) trial, which includes 18,113 patients with $\mathrm{AF}$ and at risk of stroke, a dosage of $150 \mathrm{mg} / \mathrm{d}$ of dabigatran was associated with a lower rate of stroke and systemic embolism than warfarin; both agents were associated with a similar rate of major hemorrhage. ${ }^{69}$ With a lower dose, dabigatran $(110 \mathrm{mg} / \mathrm{d})$ reduced stroke and systemic embolism similar to warfarin but caused a lower incidence of major bleeding. ${ }^{69}$

\section{COMPREHENSIVE MANAGEMENT OF PATIENTS WITH AF}

A recent trend in the management of AF involves a shift from electric end points such as rate or rhythm control to hard end points such as morbidity and mortality. ${ }^{2}$ Indeed, improving morbidity and mortality should be the prime focus of any therapy. Many patients with AF have coexisting ailments (such as hypertension, heart failure, coronary artery diseases, myocardial ischemia, diabetes) that are often more serious than AF. These diseases often develop independent of AF but may promote AF or may be aggravated by AF. A comprehensive approach to therapy addressing these comorbidities is therefore the key to reducing morbidity and mortality in patients with AF. Dronedarone has been promoted as such an agent owing to its ability to reduce stroke, blood pressure, and ventricular rate during $\mathrm{AF}$, as well as reduce the incidence of $\mathrm{AF} .{ }^{8,38,70}$ This ability of dronedarone may explain the significant reduction of cardiovascular-related hospitalization and mortality in 
patients with AF treated with dronedarone in the Placebo-Controlled, Double Blind, Parallel Arm Trial to asses the efficacy of dronedarone $400 \mathrm{mg}$ bid for the prevention of cardiovascular hospitalization and death from any cause in patients with atrial fibrillation/ flutter (ATHENA) trial. ${ }^{38}$ The anti-AF efficacy of dronedarone seems to be relatively poor. ${ }^{7-9}$ It is possible that a significant reduction in hospitalization (and, thus, morbidity) can be achieved without substantial AF suppression. All-cause mortality was not significantly reduced by dronedarone in ATHENA, ${ }^{38}$ as is the case for all large clinical trials of anti-AF agents conducted to date. $3,38,60,71,72$

The authors' recent experimental data demonstrating a potent synergistic effect of a combination of dronedarone and ranolazine to atrial-selectively suppress sodium channelmediated parameters and effectively suppress AF (see Fig. 3), ${ }^{37}$ which may represent another comprehensive approach to the management of patients with AF. Ranolazine, in addition to its potent antiarrhythmic actions, ${ }^{26,30,73,74}$ is capable of ameliorating ischemiarelated and heart failure-related symptoms, ${ }^{75-77}$ suggesting that it may suppress AF both directly (ie, electrically) and indirectly via its actions to counter AF-promoting conditions (heart failure and ischemia). Both drugs have an excellent clinically-proven safety profile.

\section{SUMMARY}

Development of safe and effective pharmacologic therapy for AF is one of the greatest unmet medical needs. Although rhythm control strategies are preferable to those of rate control, pharmacologic therapy capable of widely applicable, safe, and effective AF suppression is not available. Ion channel inhibition remains the principal strategy for suppression of AF. Practical clinical experience indicates that multiple ion channel blockers are generally more optimally effective for rhythm control of AF than ion channel-selective blockers. Concurrent inhibition of sodium and potassium ion channels is more likely to produce atria-selective suppression of sodium channel-mediated parameters, so long as dissociation of the drug from the sodium channel is rapid. Such drugs can effectively suppress AF with a relatively low or no risk of induction of ventricular arrhythmias. Upstream therapy targeting nonelectric factors such as structural remodeling may be required for optimally effective pharmacologic management. Pharmacologic strategies that aim to ameliorate both electric and structural substrates and triggers in the atrium as well as to treat $\mathrm{AF}$-associated extracardiac diseases and AF-induced adverse consequences (primarily stroke and heart failure) are likely to be most successful in reducing morbidity and mortality in patients with AF.

\section{Acknowledgments}

Financial support: Supported by grant HL47678 from NHLBI (CA) and the Masons of New York State and Florida.

\section{References}

1. Miyasaka Y, Barnes ME, Gersh BJ, et al. Secular trends in incidence of atrial fibrillation in Olmsted County, Minnesota, 1980 to 2000, and implications on the projections for future prevalence. Circulation. 2006; 114:119-25. [PubMed: 16818816]

2. Prystowsky EN, Camm J, Lip GY, et al. The impact of new and emerging clinical data on treatment strategies for atrial fibrillation. J Cardiovasc Electrophysiol. 2010; 21:946-58. [PubMed: 20384658]

3. Fuster V, Ryden LE, Cannom DS, et al. ACC/AHA/ESC 2006 guidelines for the management of patients with atrial fibrillation-executive summary: a report of the American College of Cardiology/ American Heart Association Task Force on Practice Guidelines and the European Society of Cardiology Committee for Practice Guidelines (Writing Committee to Revise the 2001 Guidelines for the Management of Patients With Atrial Fibrillation). J Am Coll Cardiol. 2006; 48:854-906. [PubMed: 16904574] 
4. Camm AJ, Kirchhof P, Lip GY, et al. Guidelines for the management of atrial fibrillation: the Task Force for the Management of Atrial Fibrillation of the European Society of Cardiology (ESC). Eur Heart J. 2010; 31(19):2369-429. [PubMed: 20802247]

5. Naccarelli GV, Gonzalez MD. Atrial fibrillation and the expanding role of catheter ablation: do antiarrhythmic drugs have a future? J Cardiovasc Pharmacol. 2008; 52:203-9. [PubMed: 18806600]

6. Zimetbaum P. Amiodarone for atrial fibrillation. N Engl J Med. 2007; 356:935-41. [PubMed: 17329700]

7. Piccini JP, Hasselblad V, Peterson ED, et al. Comparative efficacy of dronedarone and amiodarone for the maintenance of sinus rhythm in patients with atrial fibrillation. J Am Coll Cardiol. 2009; 54:1089-95. [PubMed: 19744618]

8. Singh D, Cingolani E, Diamond GA, et al. Dronedarone for atrial fibrillation: have we expanded the anti-arrhythmic armamentarium? J Am Coll Cardiol. 2010; 55:1569-76. [PubMed: 20378073]

9. Burashnikov A, Belardinelli L, Antzelevitch C. Acute dronedarone is inferior to amiodarone in terminating and preventing atrial fibrillation in canine atria. Heart Rhythm. 2010; 7:1273-9. [PubMed: 20478403]

10. Kober L, Torp-Pedersen C, McMurray JJ, et al. Increased mortality after dronedarone therapy for severe heart failure. N Engl J Med. 2008; 358:2678-87. [PubMed: 18565860]

11. Bardy GH, Lee KL, Mark DB, et al. Amiodarone or an implantable cardioverter-defibrillator for congestive heart failure. N Engl J Med. 2005; 352:225-37. [PubMed: 15659722]

12. Savelieva I, Camm J. Anti-arrhythmic drug therapy for atrial fibrillation: current anti-arrhythmic drugs, investigational agents, and innovative approaches. Europace. 2008; 10:647-65. [PubMed: 18515286]

13. Reiffel JA. Rate versus rhythm control pharmacotherapy for atrial fibrillation: where are we in 2008? J Atr Fibrillation. 2008; 1:31-47.

14. Wang ZG, Fermini B, Nattel S. Sustained depolarization-induced outward current in human atrial myocytes: evidence for a novel delayed rectifier $\mathrm{K}^{+}$current similar to Kv1.5 cloned channel currents. Circ Res. 1993; 73:1061-76. [PubMed: 8222078]

15. Nattel S, Carlsson L. Innovative approaches to anti-arrhythmic drug therapy. Nat Rev Drug Discov. 2006; 5:1034-49. [PubMed: 17139288]

16. Burashnikov A, Antzelevitch C. Atrial-selective sodium channel block for the treatment of atrial fibrillation. Expert Opin Emerg Drugs. 2009; 14:233-49. [PubMed: 19466903]

17. Burashnikov A, Antzelevitch C. New development in atrial antiarrhythmic drug therapy. Nat Rev Cardiol. 2010; 7:139-48. [PubMed: 20179721]

18. Burashnikov A, Antzelevitch C. Can inhibition of $\mathrm{I}_{\text {Kur }}$ promote atrial fibrillation? Heart Rhythm. 2008; 5:1304-9. [PubMed: 18774108]

19. Feng J, Xu D, Wang Z, et al. Ultrarapid delayed rectifier current inactivation in human atrial myocytes: properties and consequences. Am J Physiol. 1998; 275:H1717-25. [PubMed: 9815079]

20. Van Wagoner DR, Pond AL, McCarthy PM, et al. Outward $\mathrm{K}^{+}$current densities and Kv1.5 expression are reduced in chronic human atrial fibrillation. Circ Res. 1997; 80:772-81. [PubMed: 9168779]

21. Blaauw Y, Schotten U, van HA, et al. Cardioversion of persistent atrial fibrillation by a combination of atrial specific and non-specific class III drugs in the goat. Cardiovasc Res. 2007; 75:89-98. [PubMed: 17466958]

22. Ravens U. Potassium channels in atrial fibrillation: targets for atrial and pathology-specific therapy? Heart Rhythm. 2008; 5:758-9. [PubMed: 18452882]

23. Tuteja D, Xu D, Timofeyev V, et al. Differential expression of small-conductance Ca2+-activated $\mathrm{K}+$ channels SK1, SK2, and SK3 in mouse atrial and ventricular myocytes. Am J Physiol Heart Circ Physiol. 2005; 289:H2714-23. [PubMed: 16055520]

24. Diness JG, Sorensen US, Nissen JD, et al. Inhibition of small conductance Ca2+-activated potassium channels terminates and protects against atrial fibrillation. Circ Arrhythm Electrophysiol. 2010; 3:380-90. [PubMed: 20562443]

25. Li N, Timofeyev V, Tuteja D, et al. Ablation of a $\mathrm{Ca}^{2+}$-activated $\mathrm{K}^{+}$channel (SK2 channel) results in action potential prolongation in atrial myocytes and atrial fibrillation. J Physiol. 2009; 587:1087-100. [PubMed: 19139040] 
26. Burashnikov A, Di Diego JM, Zygmunt AC, et al. Atrium-selective sodium channel block as a strategy for suppression of atrial fibrillation: differences in sodium channel inactivation between atria and ventricles and the role of ranolazine. Circulation. 2007; 116:1449-57. [PubMed: 17785620]

27. Burashnikov A, Di Diego JM, Sicouri S, et al. Atrial-selective effects of chronic amiodarone in the management of atrial fibrillation. Heart Rhythm. 2008; 5:1735-42. [PubMed: 19084813]

28. Goldstein RN, Khrestian C, Carlsson L, et al. Azd7009: a new antiarrhythmic drug with predominant effects on the atria effectively terminates and prevents reinduction of atrial fibrillation and flutter in the sterile pericarditis model. J Cardiovasc Electrophysiol. 2004; 15:1444-50. [PubMed: 15610294]

29. Spinelli W, Parsons RW, Colatsky TJ. Effects of WAY-123,398, a new class III antiarrhythmic agent, on cardiac refractoriness and ventricular fibrillation threshold in anesthetized dogs: a comparison with UK-68798, E-4031, and dl-sotalol. J Cardiovasc Pharmacol. 1992; 20:913-22. [PubMed: 1282594]

30. Murdock DK, Overton N, Kersten M, et al. The effect of ranolazine on maintaining sinus rhythm in patients with resistant atrial fibrillation. Indian Pacing Electro-physiol J. 2008; 8:175-81.

31. Geller JC, Egstrup K, Kulakowski P, et al. Rapid conversion of persistent atrial fibrillation to sinus rhythm by intravenous AZD7009. J Clin Pharmacol. 2009; 49:312-22. [PubMed: 19129422]

32. Toivonen L, Raatikainen $\mathrm{P}$, Walfridsson $\mathrm{H}$, et al. A randomized, invasive cardiac electrophysiology study of the combined ion channel blocker AZD1305 in patients after catheter ablation of atrial flutter. J Cardiovasc Pharmacol. 2010; 56:300-8. [PubMed: 20588189]

33. Murdock DK, Reiffel JA, Kaliebe J, et al. The conversion of paroxysmal or initial onset atrial fibrillation with oral ranolazine: implications for a new "pill-in-pocket" approach in structural heart disease. J Atr Fibrillation. 2010; 2:705-10.

34. Roy D, Pratt CM, Torp-Pedersen C, et al. Vernakalant hydrochloride for rapid conversion of atrial fibrillation. A phase 3, randomized, placebo-controlled trial. Circulation. 2008; 117:1518-25. [PubMed: 18332267]

35. Kowey PR, Dorian P, Mitchell LB, et al. Vernakalant hydrochloride for the rapid conversion of atrial fibrillation after cardiac surgery: a randomized, double-blind, placebo-controlled trial. Circ Arrhythm Electrophysiol. 2009; 2:652-9. [PubMed: 19948506]

36. Sicouri S, Burashnikov A, Belardinelli L, et al. Synergistic electrophysiologic and antiarrhythmic effects of the combination of ranolazine and chronic amiodarone in canine atria. Circ Arrhythm Electro-physiol. 2010; 3:88-95.

37. Burashnikov A, Sicouri S, Di Diego JM, et al. Synergistic effect of the combination of dronedarone and ranolazine to suppress atrial fibrillation. J Am Coll Cardiol. 2010; 56:1216-24. [PubMed: 20883928]

38. Hohnloser SH, Crijns HJ, van EM, et al. Effect of dronedarone on cardiovascular events in atrial fibrillation. N Engl J Med. 2009; 360:668-78. [PubMed: 19213680]

39. Koren MJ, Crager MR, Sweeney M. Long-term safety of a novel antianginal agent in patients with severe chronic stable angina: the Ranolazine Open Label Experience (ROLE). J Am Coll Cardiol. 2007; 49:1027-34. [PubMed: 17349881]

40. Manning A, Thisse V, Hodeige D, et al. SR 33589, a new amiodarone-like antiarrhythmic agent: electrophysiological effects in anesthetized dogs. J Cardiovasc Pharmacol. 1995; 25:252-61. [PubMed: 7752650]

41. Varro A, Takacs J, Nemeth M, et al. Electrophysio-logical effects of dronedarone (SR 33589), a noniodinated amiodarone derivative in the canine heart: comparison with amiodarone. $\mathrm{Br} \mathrm{J}$ Pharmacol. 2001; 133:625-34. [PubMed: 11429385]

42. The Cardiac Arrhythmia Suppression Trial (CAST) Investigators. Preliminary report: Effect of encainide and flecainide on mortality in a randomized trial of arrhythmia suppression after myocardial infarction. N Engl J Med. 1989; 321:406-12. [PubMed: 2473403]

43. Cha TJ, Ehrlich JR, Zhang L, et al. Atrial ionic remodeling induced by atrial tachycardia in the presence of congestive heart failure. Circulation. 2004; 110:1520-6. [PubMed: 15381657]

44. Goette A, Bukowska A, Lendeckel U. Non-ion channel blockers as anti-arrhythmic drugs (reversal of structural remodeling). Curr Opin Pharmacol. 2007; 7:219-24. [PubMed: 17276728] 
45. Nattel S, Burstein B, Dobrev D. Atrial remodeling and atrial fibrillation: mechanisms and implications. Circ Arrhythm Electrophysiol. 2008; 1:62-73. [PubMed: 19808395]

46. Savelieva I, Camm J. Statins and polyunsaturated fatty acids for treatment of atrial fibrillation. Nat Clin Pract Cardiovasc Med. 2008; 5:30-41. [PubMed: 18094671]

47. Dawe DE, Ariyarajah V, Khadem A. Is there a role for statins in atrial fibrillation? Pacing Clin Electrophysiol. 2009; 32:1063-72. [PubMed: 19659628]

48. Burashnikov A. Are there atrial selective/predominant targets for "upstream" atrial fibrillation therapy? Heart Rhythm. 2008; 5:1294-5. [PubMed: 18774105]

49. Guerra JM, Everett TH, Lee KW, et al. Effects of the gap junction modifier rotigaptide (ZP123) on atrial conduction and vulnerability to atrial fibrillation. Circulation. 2006; 114:110-8. [PubMed: 16818812]

50. Shiroshita-Takeshita A, Sakabe M, Haugan K, et al. Model-dependent effects of the gap junction conduction-enhancing antiarrhythmic peptide rotigaptide (ZP123) on experimental atrial fibrillation in dogs. Circulation. 2007; 115:310-8. [PubMed: 17224477]

51. Burashnikov A, Antzelevitch C. Reinduction of atrial fibrillation immediately after termination of the arrhythmia is mediated by late phase 3 early after depolarization-induced triggered activity. Circulation. 2003; 107:2355-60. [PubMed: 12695296]

52. Hove-Madsen L, Llach A, Bayes-Genis A, et al. Atrial fibrillation is associated with increased spontaneous calcium release from the sarcoplasmic reticulum in human atrial myocytes. Circulation. 2004; 110:1358-63. [PubMed: 15313939]

53. Vest JA, Wehrens XH, Reiken SR, et al. Defective cardiac ryanodine receptor regulation during atrial fibrillation. Circulation. 2005; 111:2025-32. [PubMed: 15851612]

54. Burashnikov A, Antzelevitch C. Late-phase 3 EAD. A unique mechanism contributing to initiation of atrial fibrillation. PACE. 2006; 29:290-5. [PubMed: 16606397]

55. Corley SD, Epstein AE, DiMarco JP, et al. Relationships between sinus rhythm, treatment, and survival in the Atrial Fibrillation Follow-Up Investigation of Rhythm Management (AFFIRM) Study. Circulation. 2004; 109:1509-13. [PubMed: 15007003]

56. Pedersen OD, Bagger H, Keller N, et al. Efficacy of dofetilide in the treatment of atrial fibrillationflutter in patients with reduced left ventricular function: a Danish investigations of arrhythmia and mortality on dofetilide (diamond) substudy. Circulation. 2001; 104:292-6. [PubMed: 11457747]

57. Guglin M, Chen R, Curtis AB. Sinus rhythm is associated with fewer heart failure symptoms: insights from the AFFIRM trial. Heart Rhythm. 2010; 7:596-601. [PubMed: 20159046]

58. Talajic M, Khairy $P$, Levesque $S$, et al. Maintenance of sinus rhythm and survival in patients with heart failure and atrial fibrillation. J Am Coll Cardiol. 2010; 55:1796-802. [PubMed: 20413028]

59. Wyse DG, Waldo AL, DiMarco JP, et al. A comparison of rate control and rhythm control in patients with atrial fibrillation. N Engl J Med. 2002; 347:1825-33. [PubMed: 12466506]

60. Roy D, Talajic M, Nattel S, et al. Rhythm control versus rate control for atrial fibrillation and heart failure. N Engl J Med. 2008; 358:2667-77. [PubMed: 18565859]

61. Van Gelder I, Hagens VE, Bosker HA, et al. A comparison of rate control and rhythm control in patients with recurrent persistent atrial fibrillation. N Engl J Med. 2002; 347:1834-40. [PubMed: 12466507]

62. Hohnloser SH, Kuck KH, Lilienthal J. Rhythm or rate control in atrial fibrillation-Pharmacological Intervention in Atrial Fibrillation (PIAF): a randomised trial. Lancet. 2000; 356:1789-94. [PubMed: 11117910]

63. Van GI, Groenveld HF, et al. Lenient versus strict rate control in patients with atrial fibrillation. N Engl J Med. 2010; 362:1363-73. [PubMed: 20231232]

64. Cooper HA, Bloomfield DA, Bush DE, et al. Relation between achieved heart rate and outcomes in patients with atrial fibrillation (from the Atrial Fibrillation Follow-up Investigation of Rhythm Management [AFFIRM] study). Am J Cardiol. 2004; 93:1247-53. [PubMed: 15135698]

65. Padanilam BJ, Prystowsky EN. Atrial fibrillation: goals of therapy and management strategies to achieve the goals. Med Clin North Am. 2008; 92:217, xiii. [PubMed: 18061006]

66. Wolf PA, D'Agostino RB, Belanger AJ, et al. Probability of stroke: a risk profile from the Framingham study. Stroke. 1991; 22:312-8. [PubMed: 2003301] 
67. Gopinathannair R, Sullivan RM, Olshansky B. Update on medical management of atrial fibrillation in the modern era. Heart Rhythm. 2009; 6:S17-22. [PubMed: 19546032]

68. Hart RG, Pearce LA, Aguilar MI. Meta-analysis: antithrombotic therapy to prevent stroke in patients who have nonvalvular atrial fibrillation. Ann Intern Med. 2007; 146:857-67. [PubMed: 17577005]

69. Connolly SJ, Ezekowitz MD, Yusuf S, et al. Dabigatran versus warfarin in patients with atrial fibrillation. N Engl J Med. 2009; 361:1139-51. [PubMed: 19717844]

70. Connolly SJ, Crijns HJ, Torp-Pedersen C, et al. Analysis of stroke in ATHENA: a placebocontrolled, double-blind, parallel-arm trial to assess the efficacy of dronedarone $400 \mathrm{mg}$ BID for the prevention of cardiovascular hospitalization or death from any cause in patients with atrial fibrillation/atrial flutter. Circulation. 2009; 120:1174-80. [PubMed: 19752319]

71. Lafuente-Lafuente C, Mouly S, Longas-Tejero MA, et al. Antiarrhythmics for maintaining sinus rhythm after cardioversion of atrial fibrillation. Cochrane Database Syst Rev. 2007; 4:CD005049. [PubMed: 17943835]

72. Torp-Pedersen C, Moller M, Bloch-Thomsen PE, et al. Dofetilide in patients with congestive heart failure and left ventricular dysfunction. Danish Investigations of Arrhythmia and Mortality on Dofetilide Study Group. N Engl J Med. 1999; 341:857-65. [PubMed: 10486417]

73. Scirica BM, Morrow DA, Hod H, et al. Effect of ranolazine, an antianginal agent with novel electrophysiological properties, on the incidence of arrhythmias in patients with non ST-segment elevation acute coronary syndrome: results from the Metabolic Efficiency With Ranolazine for Less Ischemia in Non ST-Elevation Acute Coronary Syndrome Thrombolysis in Myocardial Infarction 36 (MERLIN-TIMI 36) randomized controlled trial. Circulation. 2007; 116:1647-52. [PubMed: 17804441]

74. Murdock DK, Reiffel JA, Kaliebe JW, et al. The conversion of paroxysmal or initial onset atrial fibrillation with oral ranolazine: implications for "pill in the pocket" approach in structural heart disease. J Am Coll Cardiol. 2010; 55:A6, E58.

75. Chaitman BR. Ranolazine for the treatment of chronic angina and potential use in other cardiovascular conditions. Circulation. 2006; 113:2462-72. [PubMed: 16717165]

76. Wilson SR, Scirica BM, Braunwald E, et al. Efficacy of ranolazine in patients with chronic angina observations from the randomized, double-blind, placebo-controlled MERLIN-TIMI (Metabolic Efficiency With Ranolazine for Less Ischemia in Non-ST-Segment Elevation Acute Coronary Syndromes) 36 Trial. J Am Coll Cardiol. 2009; 53:1510-6. [PubMed: 19389561]

77. Undrovinas AI, Belardinelli L, Undrovinas NA, et al. Ranolazine improves abnormal repolarization and contraction in left ventricular myocytes of dogs with heart failure by inhibiting late sodium current. J Cardiovasc Electrophysiol. 2006; 17:S161-77. 


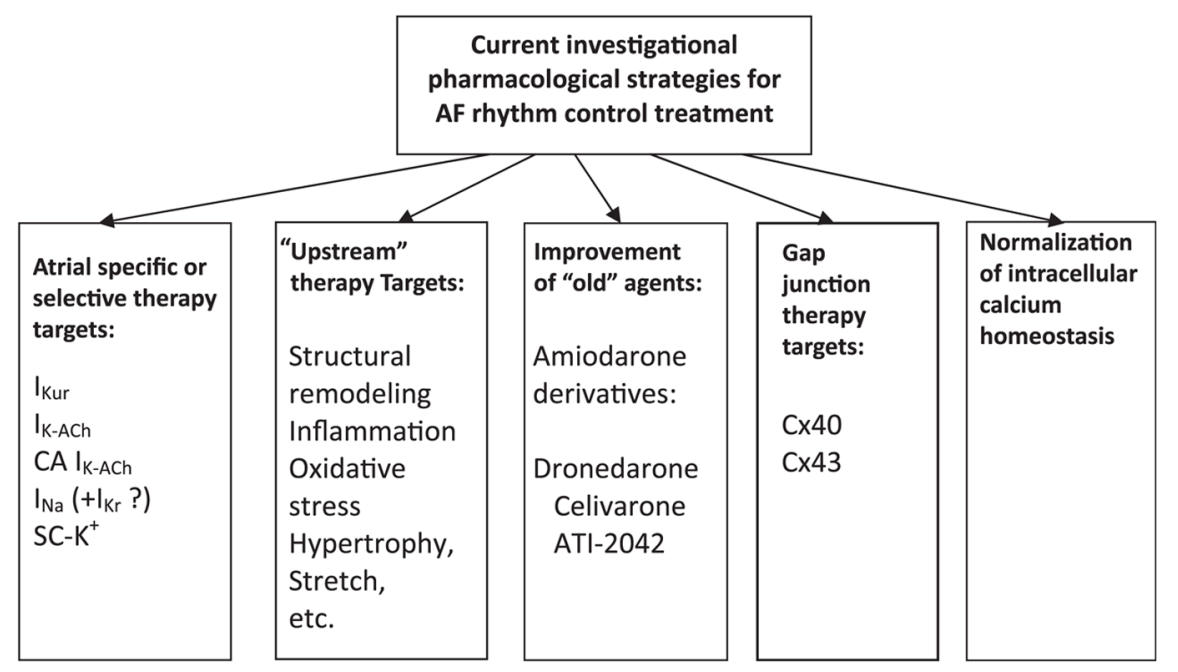

Fig. 1.

Current prominent investigational strategies for rhythm control of AF. CA, constitutively active; $\mathrm{Cx}$, connexin; $\mathrm{I}_{\mathrm{K}-\mathrm{ACh}}$, acetylcholine-regulated inward rectifying potassium current; $\mathrm{I}_{\mathrm{Kr}}$, rapidly activating delayed rectified potassium current; $\mathrm{I}_{\mathrm{Kur}}$, ultrarapid delayed rectifier potassium current; $\mathrm{I}_{\mathrm{Na}}$, early sodium current; SC-K1, small conductance calcium-activated potassium channels.

(From Burashnikov A, Antzelevitch C. New pharmacological strategies for the treatment of atrial fibrillation. Ann Noninvasive Electrocardiol 2009;14:291; with permission.) 

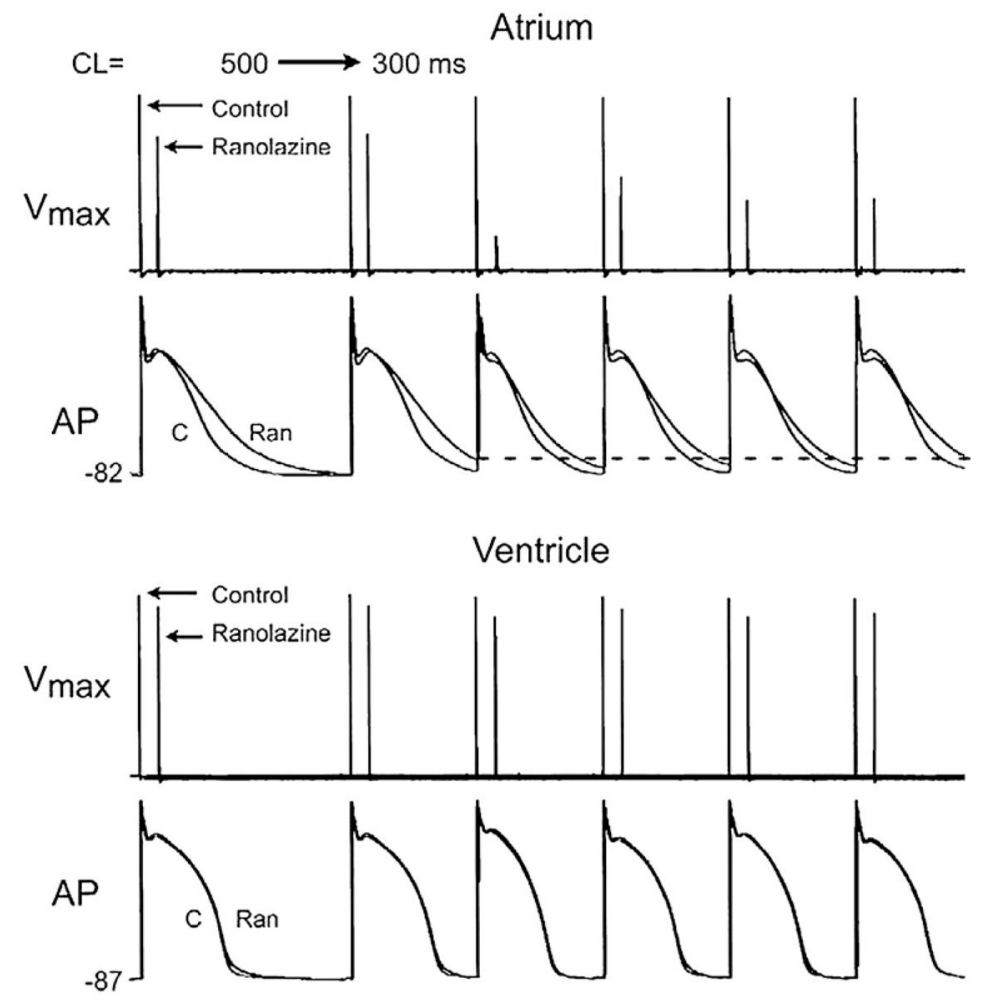

Fig. 2.

Ranolazine produces a much greater rate-dependent inhibition of the maximal action potential upstroke velocity $\left(\mathrm{V}_{\max }\right)$ in atria than in ventricles. Shown are $\mathrm{V}_{\max }$ and action potential (AP) recordings obtained from coronary-perfused canine right atrium and left ventricle before $(\mathrm{C})$ and after ranolazine $(10 \mu \mathrm{M})$ administration. Ranolazine prolongs late repolarization in atria but not ventricles (due to $\mathrm{IKr}$ inhibition ${ }^{27}$ ). Acceleration of rate then leads to elimination of the diastolic interval, during which much of the recovery from sodium channel block occurs, thus contributing to the atrial selectivity of the drug. CL, cycle length; Ran, ranolazine.

(From Antzelevitch C, Burashnikov A. Atrial-selective sodium channel block as a novel strategy for the management of atrial fibrillation. J Electrocardiol 2009;42:545; with permission.) 

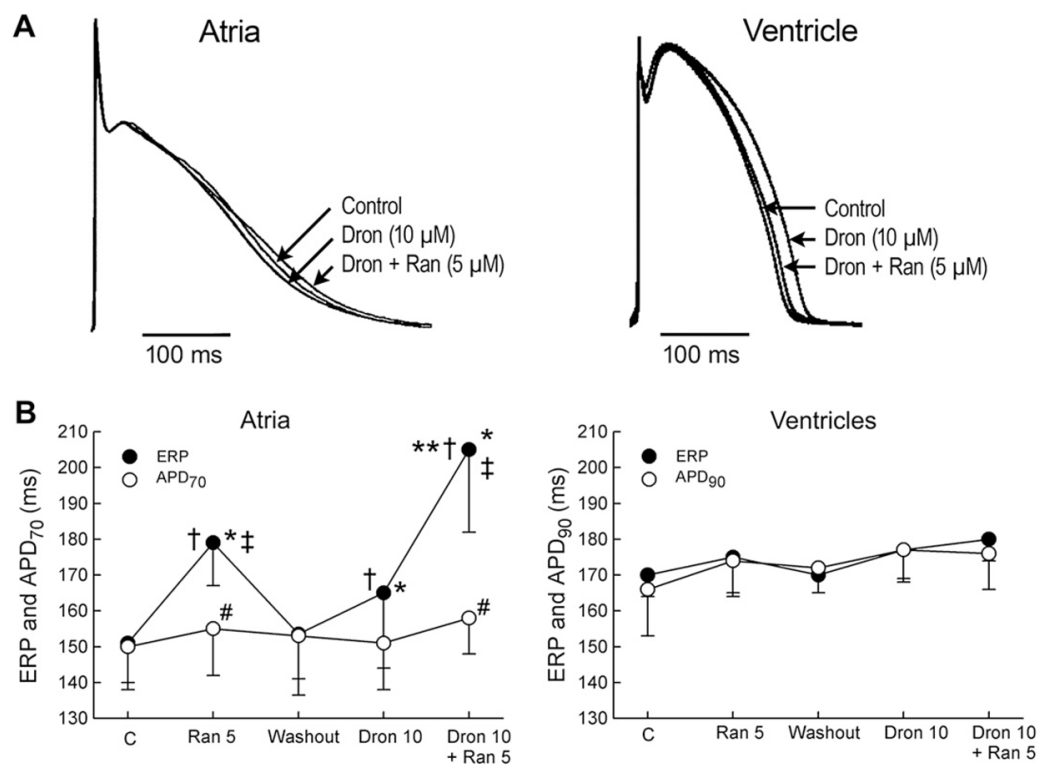

Fig. 3.

Atria-selective induction of postrepolarization refractoriness (PRR) by ranolazine (Ran), dronedarone (Dron), and a combination of both (PRR) was approximated by the difference between effective refractory period (ERP) and action potential duration (APD) measured at $70 \%$ repolarization $\left(\mathrm{APD}_{70}\right)$ in atria and by the difference between ERP and APD measured at $90 \%$ repolarization $\left(\mathrm{APD}_{90}\right)$ in ventricles; ERP corresponds to $\mathrm{APD}_{70-75}$ in atria and $\mathrm{APD}_{90}$ in ventricles. $(A)$ Shown are superimposed action potentials demonstrating relatively small changes with Dron, Ran, and their combination. (B) Summary of atria-selective induction of PRR. Ventricular data were obtained from epicardium and atrial data from endocardial pectinate muscle. $\mathrm{n}=7-8$. *,$P<.05$ versus respective control $(\mathrm{C}) ; \uparrow, P<.05$ versus washout; $\ddagger, P<.05$ versus Dron $10 ; \#, P<.05$ versus respective ERP; $* *, P<.05$, change in ERP induced by combination of Ran and Dron (from washout) versus the sum of changes caused by Ran and Dron independently (both from washout). CL $=500 \mathrm{~ms}$.

(From Burashnikov A, Sicouri S, Di Diego JM, et al. Synergistic effect of the combination of dronedarone and ranolazine to suppress atrial fibrillation. J Am Coll Cardiol 2010;56:1216-24; with permission.) 